\title{
FINITE ELEMENT MODELLING OF FOUR EDGES SIMPLY SUPPORTED STEEL PLATE UNDER IMPACT LOAD
}

\author{
C. S. Chong ${ }^{*}$, N. S. V. K. Rao, M. Mariappan
}

Faculty of Engineering, Universiti Malaysia Sabah, 88400 Kota Kinabalu, Sabah, Malaysia

Published online: 10 September 2017

\begin{abstract}
A structure may be subjected to impact load during its service life as a consequence of accidental dropping, intentional aggression and unusual purposes. In conventional static analysis, a magnification factor is used to represent the dynamic enhancement. However, it is not adequate for accurately modelling the severe loading condition. The main aim of this research is to study impact responses of four edges simply supported steel plate with finite element (FE) analysis software Abaqus, which simulated the interaction process of the colliding bodies. Hammer drop test was conducted to record the experimental behaviors of these plates. Subsequently, Navier solution was adopted to analyse the dynamic displacement of the specimens to compare the performance of the conventional method with those of Abaqus.
\end{abstract}

Keywords: impact load; finite element method; Abaqus; Hertz impact law; Navier solution.

Author Correspondence, e-mail: samchong1210@gmail.com

doi: http://dx.doi.org/10.4314/jfas.v9i3s.22

\section{INTRODUCTION}

Recent world disasters have shown that the requirement for protecting civilian and military structures from the impact load has never been greater [1]. Numerous design codes provide 
general rules for designing structures to sustain impact load [2]. Eurocode, Part 1-7 guides the designer to compute an equivalent static force on structures in an impact event with referring to the type of traffic, whereas the design has ignored the real impact process. Since impact load is characterized with maximum impulsive loading, loading condition and loading rate, structural design would not be satisfied if evaluated by static design method [3].

During the collision of the structures, contact forces that are caused by the percussion induce not only local deformation near the contact patch but also the global deformation of the structures [4]. Support frame that supports the specimen at all edges does not restrain the upward movement of the specimen. When a specimen is held with support frame, the global displacement (rebound) of the steel plate is high. Commercial FE analysis software Abaqus is a versatile modelling tool that can accurately simulate both local and global deformation. In this study, support frame is included to investigate the effectiveness of Abaqus in exploring the impact response. Commonly, four edges boundary condition can be modeled by either simulating the interaction between the colliding bodies or directly defining the movement at all edges as zero. The well-known conventional method Navier solution is only limited to model the latter boundary condition. Abaqus modeling is an expedient solution to solve this limitation.

According to [5], the characteristic of the utilized contact force model plays a main role for simulating the engineering employments and investigating the response of the solid within contact-impact events in body contact interaction. They also stated that the contact force model is usually formulated using the Hertz contact theory and presently included the dissipation energy that produces during the colliding process with a damping parameters. The nonlinear Hertzian contact law was also deployed by [6] for examining the contact force between the plate and projectile. This dissipative type of Hertz contact law is extensively researched in the discrete element simulations [7]. Hence, Hertz contact law is adopted to study the applied impact force in this research. Navier type solution is revealed as a simple solution and has good accuracy for obtaining the displacement field of rectangular plates since only sine-wave term is included [8].

Plates are common structural elements that may subject to a wide range of static and dynamic 
loads [9]. They are ubiquitous in engineering purposes due to their indispensable in various structural components [10]. In [1] has suggested that a bulky shield, which is thin to intermediately thick metallic plate can be used for covering the sensitive areas to protect the possible impact damage. Hammer drop machine is an effective experiment to examine the behavior of the structure due to the load of intermediate rate domain, which is extremely difficult to assess [11]. In this study, hammer drop test is conducted experimentally and modelled with Abaqus modeling to investigate the four edges simply supported steel plates. Hertz contact law and Navier solution are implemented to study the contact force and the dynamic displacement of the steel plates.

Hammer drop test is an effective experiment to investigate the impact response of the structures. It mainly involves four essential components which are a hammer, the specimen, support and a data acquisition system.

\subsection{The Experiment Set-Up}

In hammer drop test, hammer falls freely with gravitational acceleration to apply an impact force to the specimen. It was fabricated by high strength steel to ensure the impaction is the type of hard contact. A semi-spherical steel part was welded to the bottom part of the hammer. Hence, the applied impact force is transmitted to the specimen at a small specific area. Different amount of striking force can apply to the specimen via varied hammer drop height. In this paper, three different drop heights which are $0.05 \mathrm{~m}, 0.10 \mathrm{~m}$ and $0.15 \mathrm{~m}$ were included to study the impact response of the steel plate. When the specimen is hit, it has to be restrained on the rigid and firm base, which is known as the support. There are various types of support namely simply support, fixed-fixed support, etc. In this study, a support frame was used to provide support at all four edges of the steel plate. The steel plate that had been examined is types 4340 steel. Its dimension is $400 \mathrm{~mm}$ x $400 \mathrm{~mm}$ x $3.5 \mathrm{~mm}$. When the percussion load applied onto the steel plates, it was acting as a concentrated point load. Different points of the steel plate respond distinctly toward impact load.

Even though steel plate reacts symmetrically with respect to the center impaction, two various sensors were located at two symmetric identical positions as described in Fig. 1 for attesting the accuracy of the experimental results. During the impact force transmits to the steel plate 
and components respond to the percussion, a data acquisition system is implemented for recording the response. The arrangement of the hammer drop test is illustrated in Fig. 1.

\subsection{Data Acquisition System}

A data acquisition system which is also called a monitoring system is an aggregation of hardware and software components that permits the computer to evaluate the physical phenomena of the real world from sensors [12]. It not only receives data from a physical process or experiment, but also displays and stores the data or the characteristics of the data that extracted through its processing.

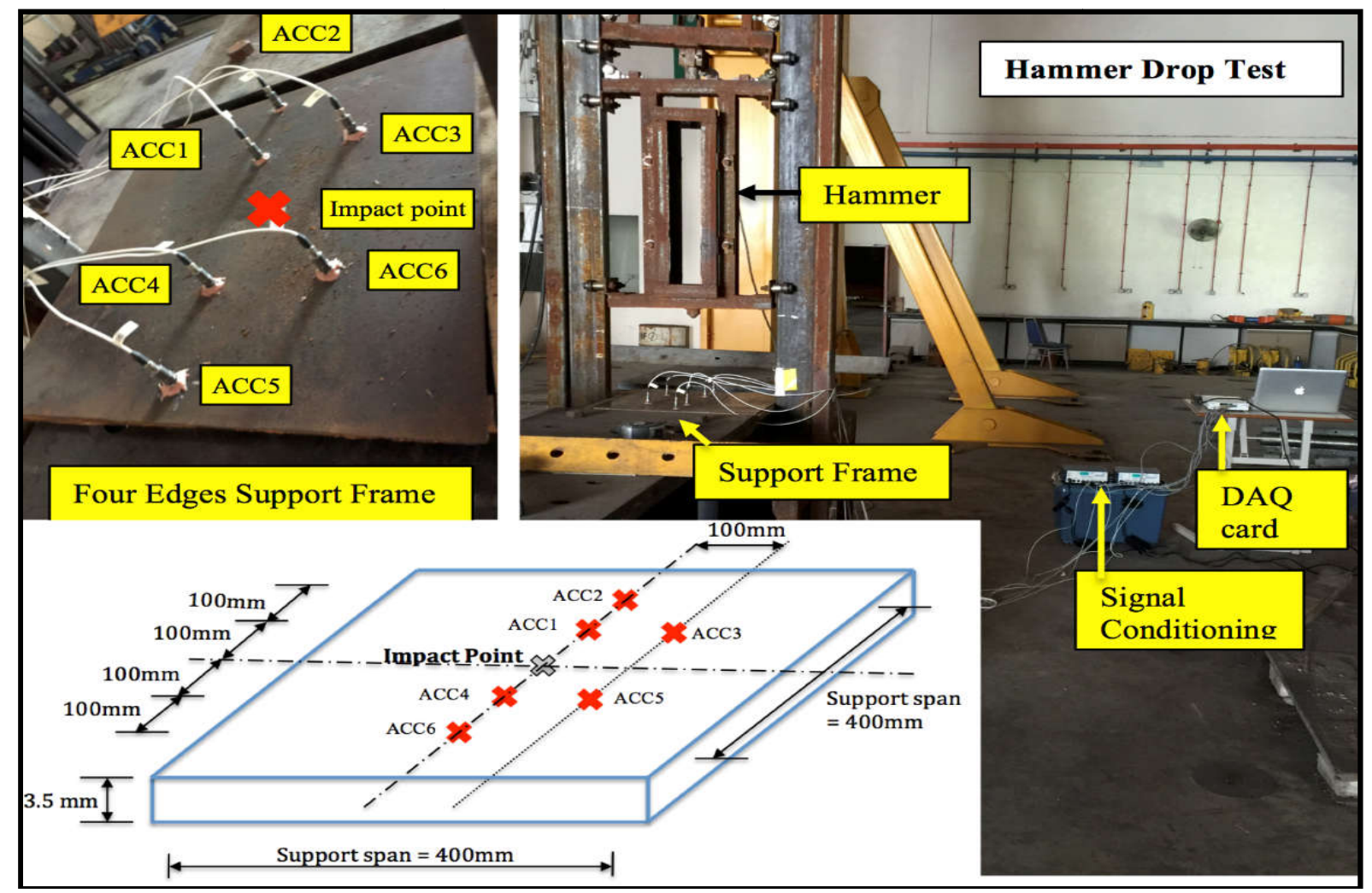

Fig.1. The arrangement of hammer drop test

In general, a data acquisition system requires four vital instruments, which provide significant purpose in recording authentic data from a physical process. They are sensor, signal-conditioning device, data acquisition and analysis hardware (DAQ card) and application software (computer). For evaluating the authenticated data, sensor transforms the information about physical phenomena in the real world process into a low-power electrical signal. Then, this low-power electrical signal is conveyed to the signal-conditioning device. In addition to amplify the low-level signal, the signal-conditioning accessory also filters and isolates the signal to obtain reliable measurements. DAQ card is an interface between the 
application software and the physical phenomena of the real world. By implementing the input/output $(\mathrm{I} / \mathrm{O})$ process, the DAQ card enables the computer to communicate with the experiment. Lastly, the application software is an effective tool to allow the researcher or engineer for reading sensors and processing the evaluated data, i.e. plotting, control, saving and manipulating the data.

In this research, six numbers of 350B03 PCB piezoelectric accelerometer which were named as ACC1, ACC2, ACC3, ACC4, ACC5 and ACC6 were deployed to record the dynamic data of the steel plate at six different locations. These positions are shown in Fig. 1. The piezoelectric material of the piezoelectric accelerometer has high stiffness. Its natural frequency can achieve to $100 \mathrm{kHz}$. Therefore, piezoelectric accelerometer permits the high frequency measurement and is an exceptional sensor for recording impact, shock and seismic response. Subsequently, two units of model 482C05 piezotronics, four-channel ICP@ sensor signal-conditioner were adopted to amplify and improved the accuracy of the sensor-recorded signal. For connecting the accelerometers with the application software, LabVIEW, the National Instrument USB-6281, 18 bit, $625 \mathrm{kS} / \mathrm{s}$ M series, Multifunction DAQ card was deployed. With LabVIEW software, the dynamic displacements of the steel plate at the six positions were measured at $50 \mathrm{kHz}$ frequencies that evaluated each data every $0.01 \mathrm{~ms}$. The corresponding results are discussed in section 2.

\subsection{Analytical Method-Analysis of Hammer Drop Test}

In [13] pioneered the development of the Hertz theory of impact to study the percussion of solid structures with spherical surfaces. This classical theory of impact due to Hertz, which is also known as the Hertz contact law, is a quasi-static theory. Therefore, it postulates that the deformation is localized in the vicinity of the contact patch [14]. According to [4], Hertz's theory is a very useful approach for analyzing the collisions between rigid compact structures where the contact area is small if compare to the size of the colliding body. Hertz's theory evaluates the deformation near the contact point, $\alpha$ and the contact forces, $F$ by referring to the geometric and material properties of the colliding structures. The Hertz theory of impact is formulated as Equations (1) to (6).

$F=k \alpha^{\frac{3}{5}}$ 
$k=\frac{4}{3} R^{\frac{1}{2}} E^{*}$

$\alpha=\frac{15}{16} \frac{m *\left[V_{z}(1+e]^{2}\right.}{R^{\frac{1}{2}} E^{*}}$

$\frac{1}{R}=\frac{1}{R_{1}}+\frac{1}{R_{2}}$

$\frac{1}{E^{*}}=\frac{1-v_{1}^{2}}{E_{1}}+\frac{1-v_{2}^{2}}{E_{2}}$

$\frac{1}{m^{*}}=\frac{1}{m_{1}}+\frac{1}{m_{2}}$

$k$ is the stiffness constant that depends on the geometry and material behavior of the colliding structures. $V_{z}$ is the impact velocity of the projectile and $e$ is the coefficient of restitution of the impactor. $R_{1}$ and $R_{2}$ are the radius of the projectile and specimen. $E_{1}$ and $E_{2}$ are the elasticity modulus of the impactor and the specimen. $v_{1}$ are and $v_{2}$ are the Poisson's ratio of the impactor and the plate. $m_{1}$ and $m_{2}$ are the mass of the projectile and specimen.

In [15] has formulated the Hertz contact force $f(t)$ with respect to time $t$ as Equation (7). In [16] defined the impact forces of the drop mass $F(t)$ based on the equivalence of the impulse and momentum as Equation (8). Since the maximum impact force occurs when its sine function equal to one, the contact time $T_{c}$ in this study is evaluated as Equation (9).

$f(t)=F * \sin \left(\frac{\pi t}{T_{c}}\right)^{\frac{3}{2}}$

$F(t)=m_{1} V_{z}(1+e) \frac{\pi}{2 T_{c}} \sin \frac{\pi}{2 T_{c}}$

$T_{c}=m_{1} V_{z}(1+e) \frac{\pi}{2 F(t)}$

In terms of Navier solution, the displacement $w(x, y, t)$ of the four edges simply supported rectangular plate is formulated as the function of a double trigonometric series of the coefficient $a_{m m}$. By implementing the equation of motion for free vibration of the plate into the Navier solution for covering the inertial effect of the impact forces and subsequently considering that the equivalence of the impulse force with the change of the momentum, the dynamic displacement of the four edges simply supported rectangular plate can be obtained using Equation (10) to (13) [17]. 


$$
\begin{aligned}
& w(x, y, t) \\
& =\frac{4 m_{1} V_{z}(1+e)}{\rho h a b} \sum_{m=1}^{\infty} \sum_{n=1}^{\infty} \sin \frac{m \pi x_{I}}{a} \sin \frac{m \pi y_{I}}{b} \sin \frac{m \pi x}{a} \sin \frac{m \pi y}{b} \frac{e^{-\xi \omega t} \sin \left(\omega_{d} t\right)}{\omega_{d}} \\
& \omega_{d}=\omega_{n} \sqrt{1-\xi^{2}} \\
& \omega_{n}=\pi^{2} \sqrt{\frac{D}{\rho h}}\left[\left(\frac{m}{a}\right)^{2}+\left(\frac{n}{b}\right)^{2}\right] \\
& D=\frac{E_{2} h^{3}}{12\left(1-v_{2}^{2}\right)}
\end{aligned}
$$

$\rho$ and $h$ are density and thickness of the plates. $a$ and $b$ are the width and length of the plate. $x$ and $y$ are the coordinate of the plate, which the dynamic displacement is evaluated due to the impaction at points $x_{I}$ and $y_{I}, m$ and $n$ are the series number of the equation. $D$ is the flexural rigidity of the plate. These equations were utilized to evaluate the displacement response of the four edges simply supported steel plate.

\section{METHODOLOGY}

In order to simulate the dynamic response of four edges simply supported rectangular steel plate in the hammer drop test, hammer, steel plate and support frame were modelled with the FE commercial package software Abaqus. Fig. 2 depicts the FE modelling of the hammer drop test. For simulating the hammer impaction, two analysis steps, which were Step-1 and Step-2 were employed. In the first analysis step, Step-1, the gravity load $\left(9.81 \mathrm{~m} / \mathrm{s}^{2}\right)$ was applied on the hammer model of respective drop heights. The hammer should intersect with the steel plate model at the starting of Step-2. The general contact algorithm of Abaqus/Explicit was used to simulate the contact interaction behavior among the hammer, specimen and support models. The dynamic response of the steel plate due to the percussion of the hammer was recorded during the Step-2.

\subsection{The FE Models}

In this research, the steel plate was modelled as three-dimensional deformable solid. So, that its deformation performances in hammer drop test can be accurately captured with FE Abaqus simulation. The tested steel plate was steel type 4340. Its material properties were modeled 
using Johnson-cook plasticity and Johnson-Cook dynamic failure model. Since the symmetrical results were obtained from the FE analysis, only the FEM results of three different positions were included in the discussion. Before the steel plate model can be widely implemented to investigate the impact response due to different hammer height, various sizes of the mesh elements were utilized to ensure the suitability of the model. Ten different mesh element sizes had been modeled and their obtained contact force results are shown in Fig. 3 . Via the contact forces that were analyzed from Abaqus and Hertz contact law, it can be concluded that total mesh elements of 5292 where the uniform element size if $10 \mathrm{~mm} \times 10$ $\mathrm{mm} \times 1.167 \mathrm{~mm}$, has the highest accuracy and computational efficiency.
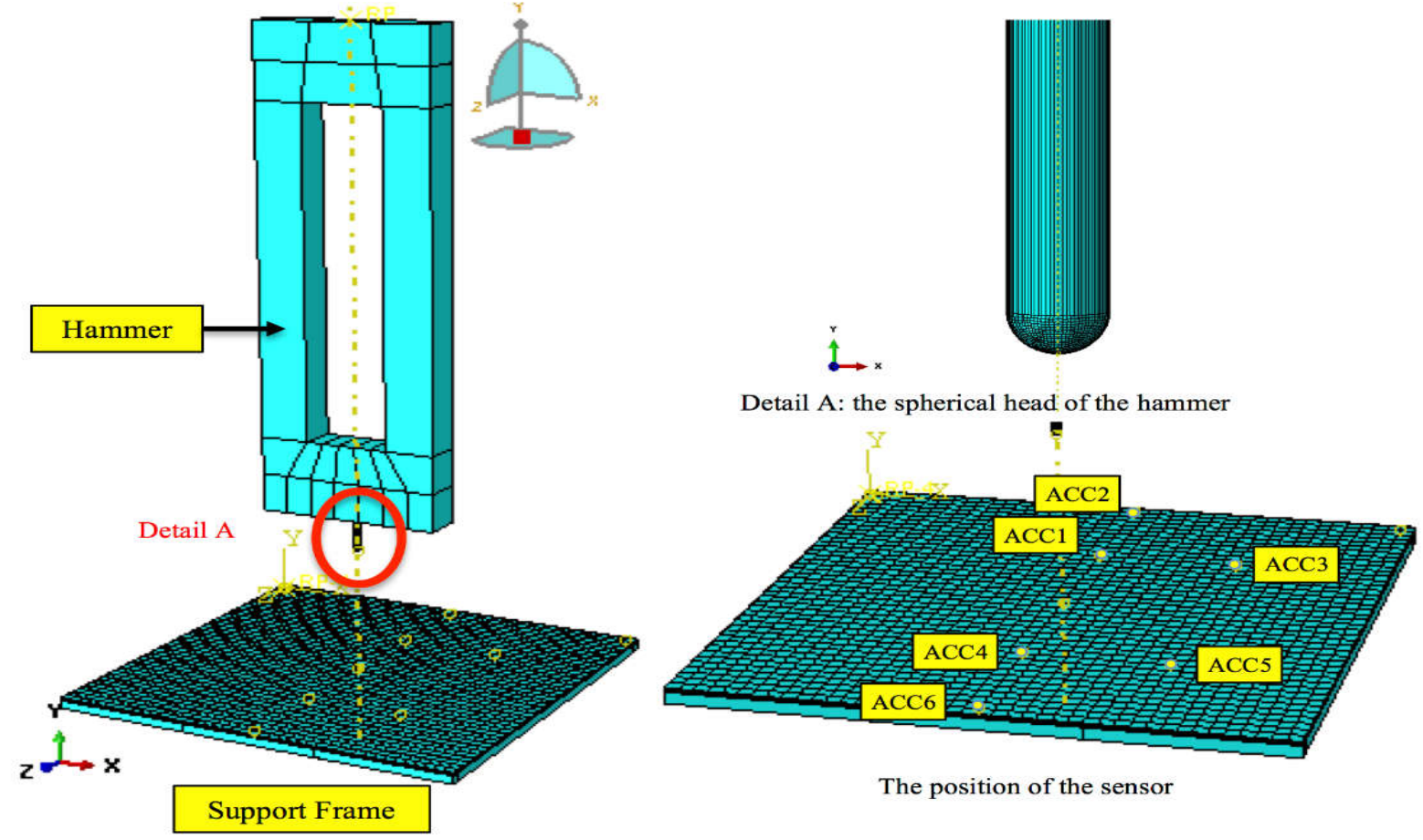

Fig. 2. FE modeling of the hammer drop test

Within hammer drop test, the hammer impacts the steel plate to transmit hard contact force onto the steel plate for investigating its impact response. Hence, the hammer needs to be defined as a rigid body in Abaqus. Similarly, the support frame is also specified as a rigid body for supporting the steel plate to receive the impaction. Since these two models were also modeled as rigid bodies, their mesh sizes do not influence the computational time. However, the spherical head of the hammer should be meshed with fine elements, so that the penetration between hammer and steel plate can be avoided. This penetration is not usually observed in the experiment. Both of hammer and support frame were also modelled using elastic material 
properties of steel.

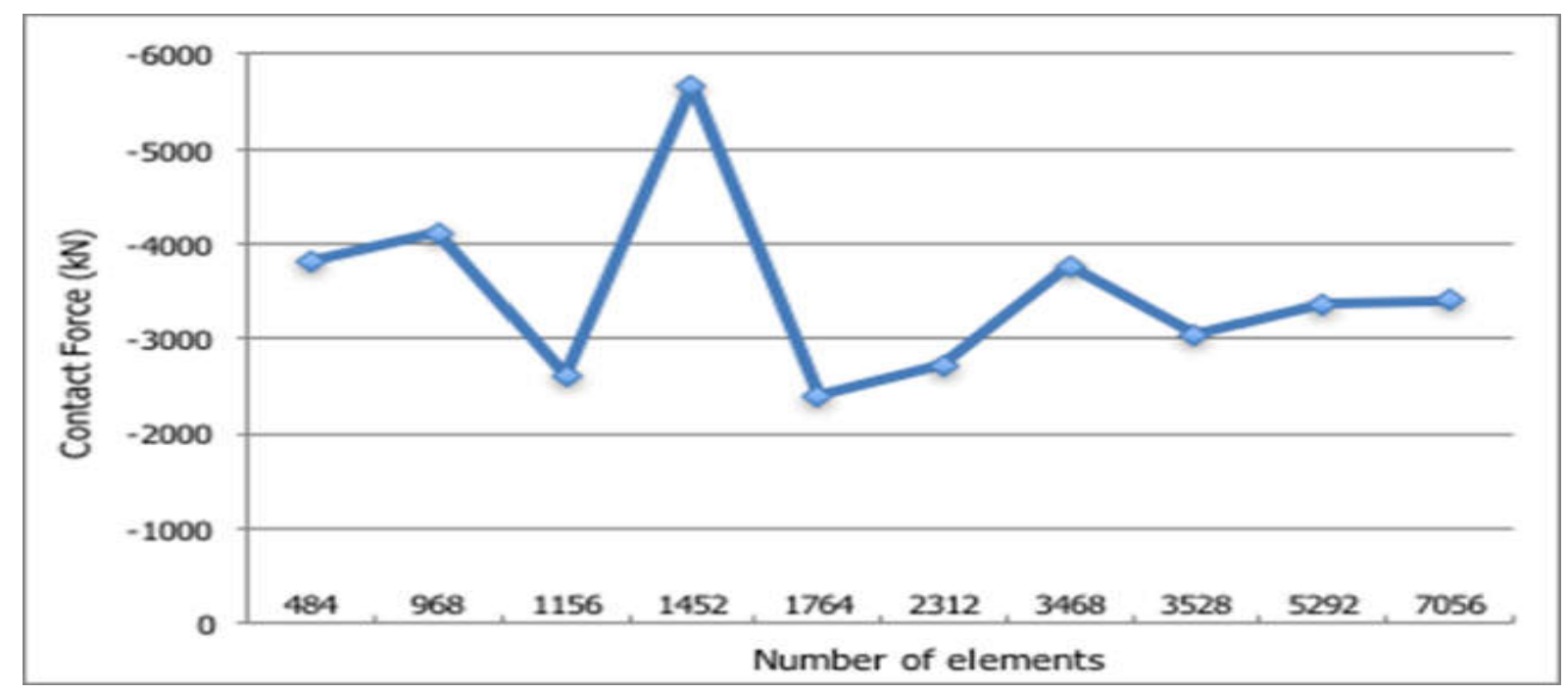

Fig.3. Contact Forces from Abaqus analysis with different number of elements

\subsection{Boundary Conditions of FE Models}

Generally, Abaqus imitates the boundary condition in two ways. It either models the interaction between the support and the specimen or defines directly the boundary condition in the BCs module of the Abaqus to constrain the upward and downward movements of the specimen at four of its edges. Both of these modeling methods are included in this study. When modeling the support frame and simulating the interaction between the specimen and the support frame, the upward movement of the steel plate is not restrained, thus, it has high rebound displacement. This rebound displacement is classified as the global deformation. The deformations at six points where the experimental results had been evaluated through the piezoelectric accelerometers were also obtained.

In the second case, where four edges simply support condition was modelled by confining the upward and downward movement of the specimen, the analysis is similar to those of Navier solution. Since the upward and downward movement of the steel plate is restrained, its global deformation due to the rebound is small. The local deformation is crucial in this case. Hence, the mesh size in this case has to be finer than those in the support frame case. For efficiently simulating the response, symmetry condition had been utilized for reducing the full size of the steel plate to quarter size. While only quarter steel plate was modelled, the total impact load that transmitted to the model was reduced quarterly. For verifying the accuracy of the symmetrical model, the obtained results were compared first with those recorded from the full 
model. The obtained dynamic behavior of the steel plate is discussed in section 3 .

\section{RESULTS AND DISCUSSION}

In Abaqus/Explicit analysis, the contact force that applies to the steel plate from the free fall hammer is computed based on the simulation of their contact interaction which implements the contact formulation. This concept is distinct with those of the Hertz impact law. However, both of these theories are well known approach in modeling the contact forces. Since Abaqus is a finite element method, the mesh of its model is crucial in influencing the accuracy of the modeling result. 10 different mesh element sizes had been modeled and their evaluated contact force results were compared to those computed from Hertz impact law. For maintaining good accuracy and time-effective simulation, the uniform element size $(10 \mathrm{~mm} \mathrm{x}$ $10 \mathrm{~mm} \times 1.167 \mathrm{~mm}$ ) of the steel plate was used in this study. The total element for meshing the steel plate with this element size is 5292. Table 1 shows the contact forces that acquired with Abaqus and Hertzian contact law. They have a very satisfactory agreement.

Table 1. Contact forces of steel plates (support frames)

\begin{tabular}{cccc}
\hline $\begin{array}{c}\text { Hammer } \\
\text { Height }\end{array}$ & $\begin{array}{c}\text { Hertz's } \\
\text { Contact Law }\end{array}$ & ABAQUS & $\begin{array}{c}\text { Differences With Respect } \\
\text { to Hertz's Contact Law }\end{array}$ \\
\hline $0.05 \mathrm{~m}$ & $3245.52 \mathrm{~N}$ & $3366.94 \mathrm{~N}$ & $3.74 \%$ \\
$0.10 \mathrm{~m}$ & $3952.62 \mathrm{~N}$ & $3887.59 \mathrm{~N}$ & $1.65 \%$ \\
$0.15 \mathrm{~m}$ & $5041.27 \mathrm{~N}$ & $5010.35 \mathrm{~N}$ & $0.61 \%$ \\
\hline
\end{tabular}

Fig. 4 shows the displacement responses of the steel plate with simply supported frame due to the drop of the $0.05 \mathrm{~m}$ height hammer at locations ACC1 or ACC4, ACC2 or ACC6 and ACC3 or ACC5. From these figures, the first downward displacements indicate the local deflection of the steel plate. The local deflections of ACC1 or ACC4 and ACC3 or ACC5 were about $4 \mathrm{~mm}$ and $2.5 \mathrm{~mm}$ respectively. The accelerometers ACC1 and ACC4 were positioned nearer to the impact point than the ACC3 and ACC5, hence the local deflections of ACC1 or ACC4 were higher. Accelerometers ACC2 and ACC6 were located at the support, so their local deflections were nearly zero. After the hammer impacted the steel plate, rebound of the hammer and steel plates happened and this phenomenon is captured clearly from the 
figure. In overall, six sensors and six different positions of the steel plate in Abaqus analysis had obtained the similar rebound displacement which was around $7 \mathrm{~mm}$. Since the rebound of a steel plate happens as a global displacement, all positions of the steel plate should displace with same rebound distance. Therefore, it can conclude from Fig. 4 that all the local and global displacement of the steel plates at different positions which were recorded from experiment and modelled from Abaqus, have good similarity. The difference between the values of Abaqus and experiment are all lesser than $11.5 \%$.
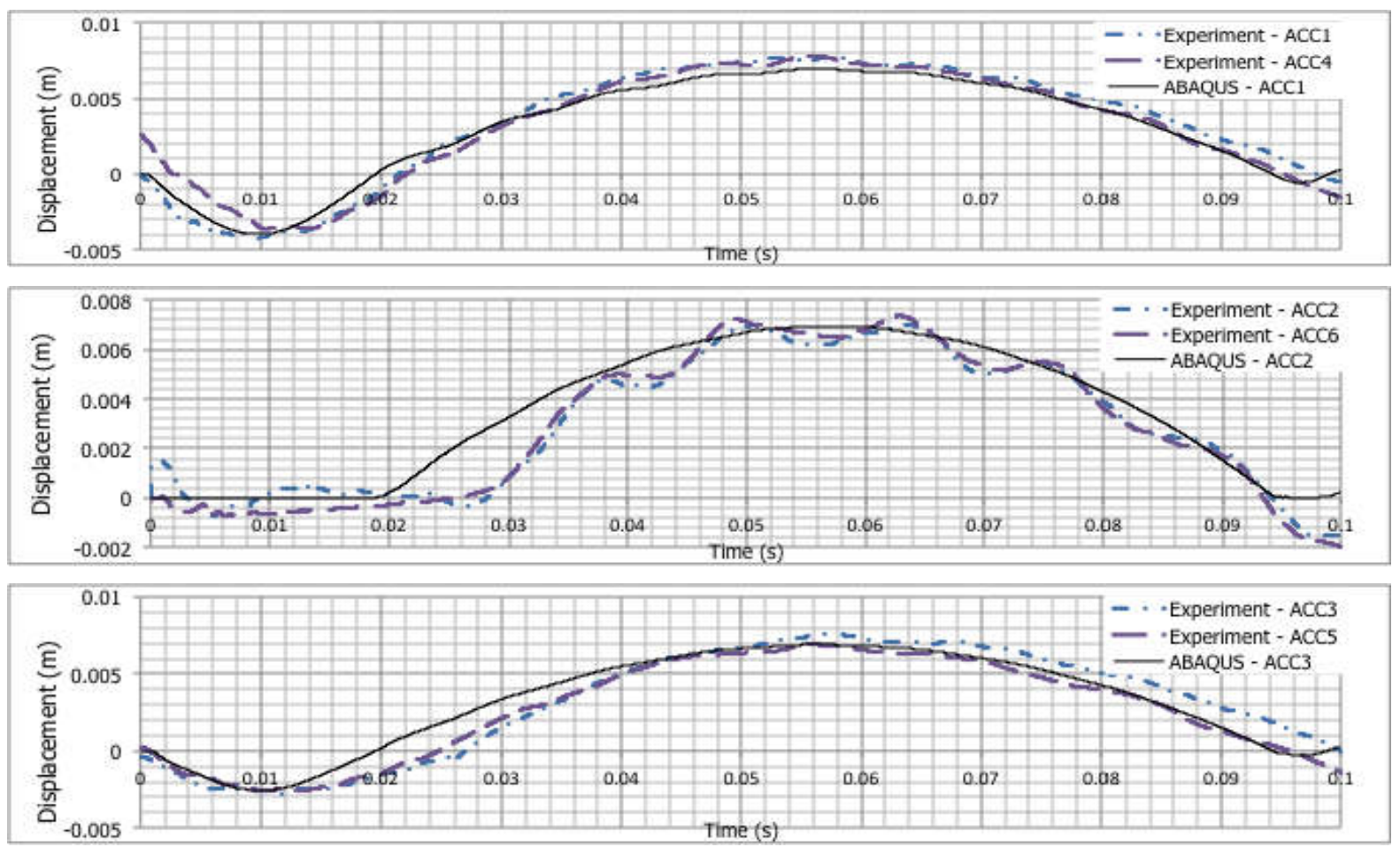

Fig.4. The displacement of steel plate (simply support frame) due to the drop of the $0.05 \mathrm{~m}$

$$
\text { height hammer }
$$

Correspondingly, the dynamic displacements of steel plate with simply support frame towards the impaction of $0.10 \mathrm{~m}$ height hammer at six different positions are illustrated in Fig. 5. For this case, the local deflection that recorded at ACC1 or ACC4 and ACC3 or ACC5 were around $5 \mathrm{~mm}$ and $3.5 \mathrm{~mm}$ respectively. These local deflections are slightly greater than those due to impaction of the hammer with $0.05 \mathrm{~m}$ height. Moreover, the global displacement of the steel plate, which was about $12 \mathrm{~mm}$ were recorded experimentally and modelled with Abaqus. If comparing to those due to hammer height $0.05 \mathrm{~m}$, the global displacement is higher. Thus, the rebound of the steel plate may be elevated if the impaction is increased. All the obtained 
results of Abaqus modelling and experiment in this case have differences less than $10.5 \%$.

For case of $0.15 \mathrm{~m}$ hammer height, the dynamic displacements of steel plate with simply support frame at six different positions are described in Fig. 6. Same as previous cases, the local deflection at ACC1 or ACC4 which was about $6 \mathrm{~mm}$ is slightly higher than those from ACC3 or ACC5 that had value $4.5 \mathrm{~mm}$. Fig. 6 also once again proves that the global displacement of all these positions were approached each other as $17 \mathrm{~mm}$. It also shows that the rebound of the steel plate is greater than those due to drop of $0.05 \mathrm{~m}$ and $0.10 \mathrm{~m}$ hammer. In this case, the values that were evaluated from the Abaqus modelling and experiment are less than $8.5 \%$.

While both the upward and downward movements of the steel plate on all four edges are eliminated by directly defining the boundary condition at these edges, the rebound of the whole steel plate is also restrained. Without this upward rebound, the rebound of the hammer is lesser than those in the support frame case. This phenomenon can be captured by Hertz impact theory by reducing the net value of the coefficient of restitution. Hence, more impact forces are transmitted into the steel plate in this case if compare to those of the support frame. The contact forces that were computed by Hertz impact law and Abaqus are listed in Table 2. Since the differences of the results are lesser than $4 \%$, they can be considered as good approaches in evaluating the contact force.

Table 2. Contact forces of steel plates (boundary conditions)

\begin{tabular}{cccc}
\hline Hammer Height & $\begin{array}{c}\text { Hertz's } \\
\text { Contact Law }\end{array}$ & ABAQUS & $\begin{array}{c}\text { Differences With Respect to } \\
\text { Hertz's Contact Law }\end{array}$ \\
\hline $0.05 \mathrm{~m}$ & $7205.98 \mathrm{~N}$ & $7482.76 \mathrm{~N}$ & $3.84 \%$ \\
$0.10 \mathrm{~m}$ & $10925.90 \mathrm{~N}$ & $10901.68 \mathrm{~N}$ & $0.22 \%$ \\
$0.15 \mathrm{~m}$ & $13935.16 \mathrm{~N}$ & $13639.64 \mathrm{~N}$ & $2.12 \%$ \\
\hline
\end{tabular}

The dynamic displacements that were computed from Abaqus and Navier solution are illustrated in Fig. 7. When the hammer collided the specimen from $0.05 \mathrm{~m}$ height, the local displacements that calculated with Navier solution and Abaqus were also roughly equal to 2.1 $\mathrm{mm}$ (at ACC1). However, the local displacement at ACC3 which was evaluated with Navier solution $(1.6 \mathrm{~mm})$ was slightly higher than those of Abaqus $(1.2 \mathrm{~mm})$. As hammer height 
elevated to $0.10 \mathrm{~m}$, the local displacements at ACC1 that computed with Navier solution and Abaqus simulation still had good agreement where both of the solutions also obtained local displacement of about $2.7 \mathrm{~mm}$. The local displacement at ACC3 also is higher if calculated with Navier solution which was around $1.9 \mathrm{~mm}$, whereas those obtained using Abaqus was near to $1.5 \mathrm{~mm}$. Both of these methods obtained zero displacement at ACC2, since ACC2 locates at the support edges.
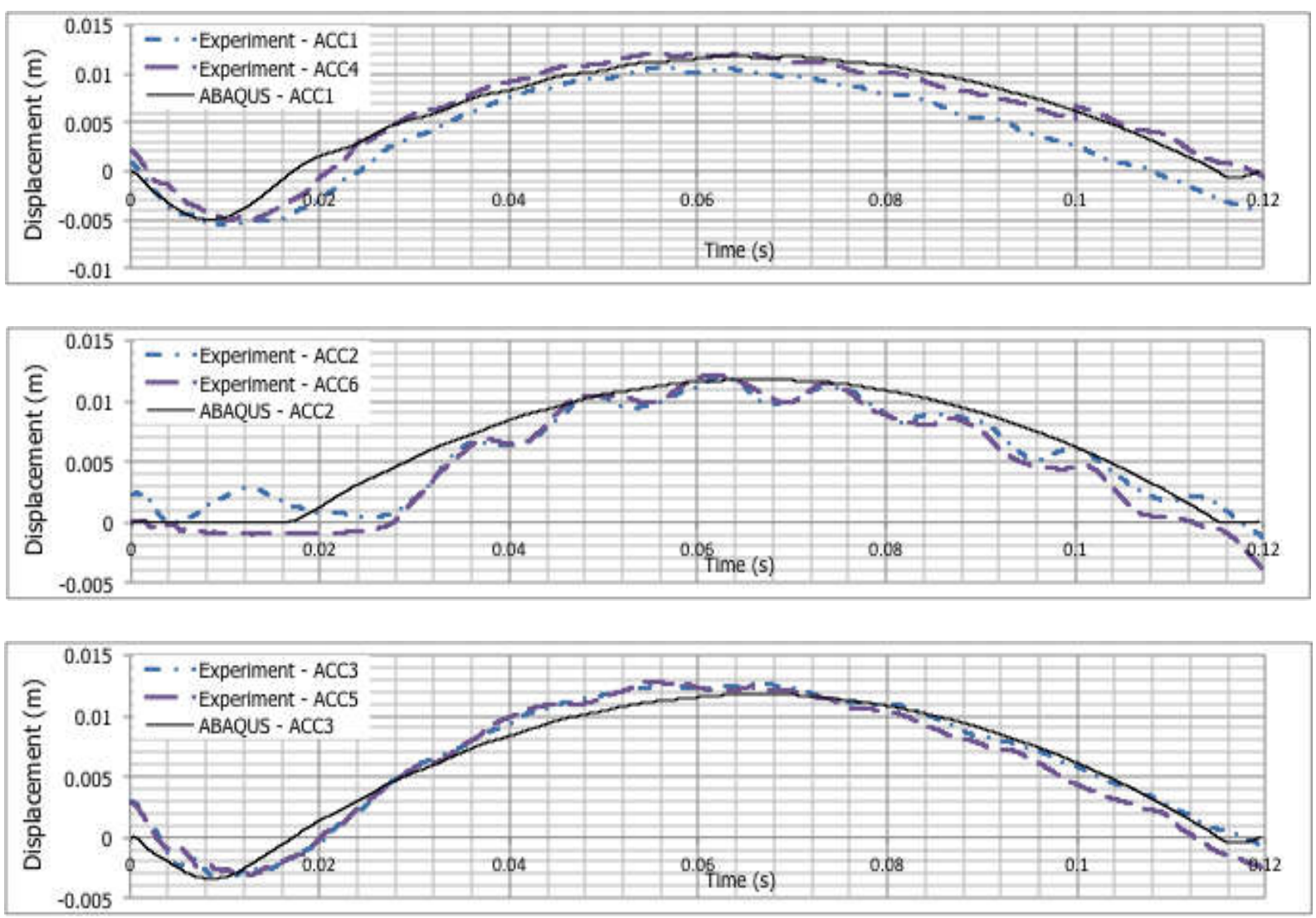

Fig.5. The displacement of steel plate (simply support frame) due to the drop of the $0.10 \mathrm{~m}$ height hammer

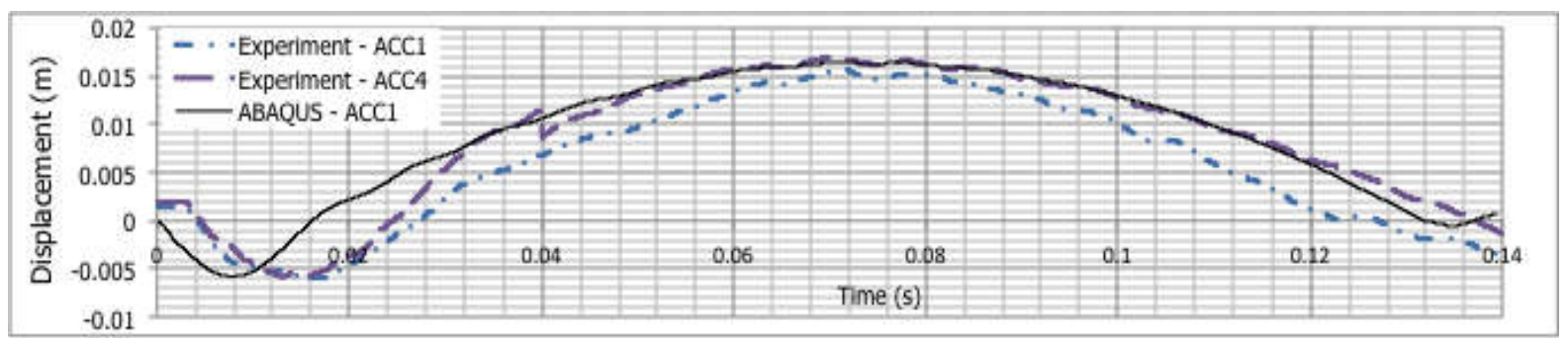



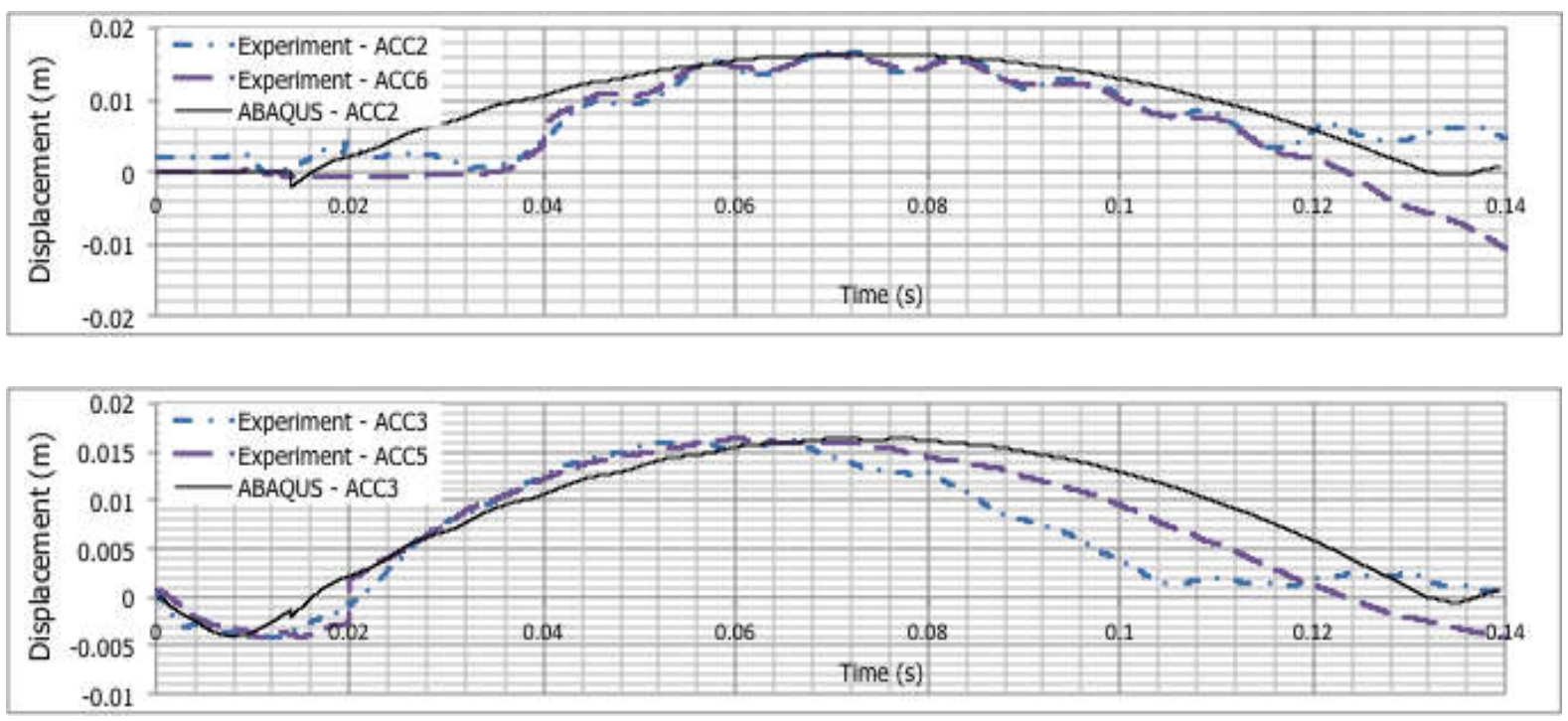

Fig.6. The displacement of steel plate (simply support frame) due to the drop of the $0.15 \mathrm{~m}$ height hammer
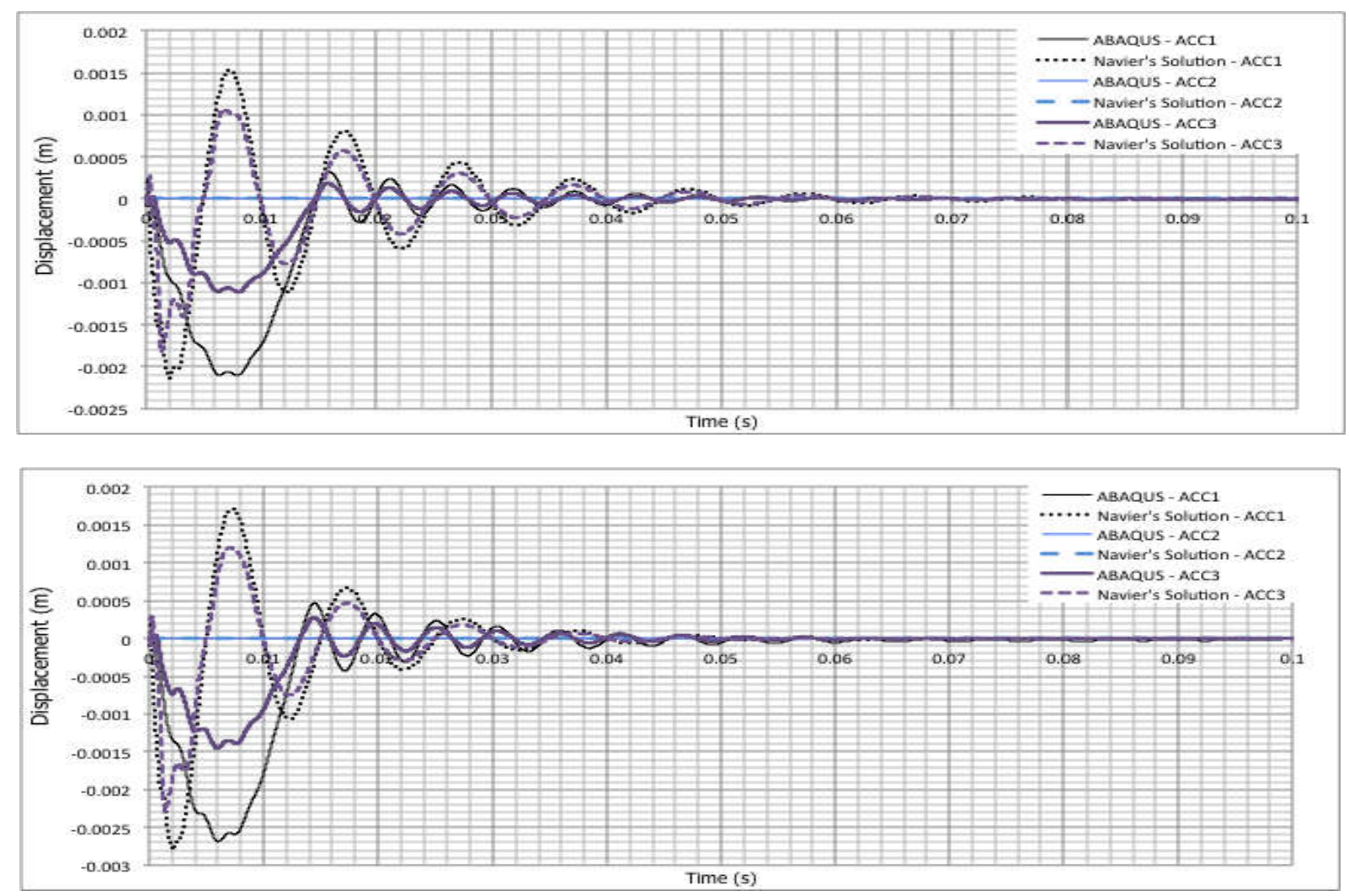


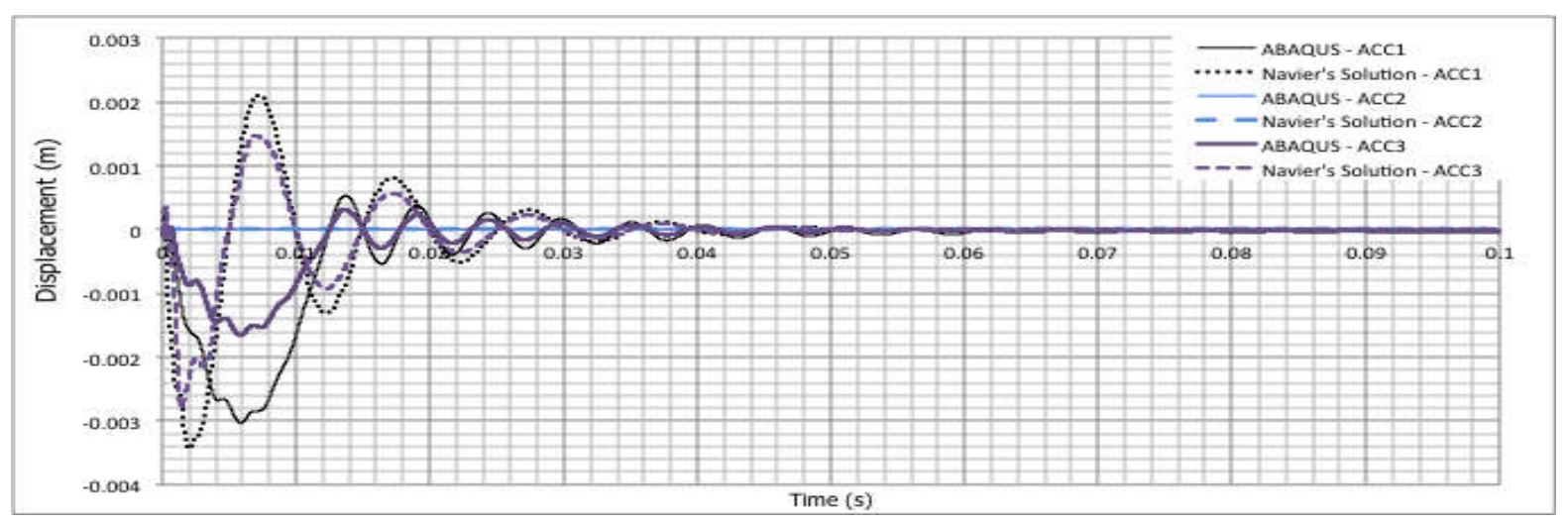

Fig.7. The displacement of steel plate (boundary condition) due to the drop of the hammer

For the hammer height of $0.15 \mathrm{~m}$, local displacements at ACC1 were $3.4 \mathrm{~mm}$ (with Navier solution) and $3.1 \mathrm{~mm}$ (with Abaqus). In contrast to the previous hammer heights, the similarity of these results is not so well. This may because plasticity properties had been considered in Abaqus simulation and only elasticity analysis was included in the Navier solution. It also causes the distinction between local displacements at ACC2 that calculated from Navier solution and Abaqus simulation. Nevertheless, the differences of local displacements that were captured from Navier solution and Abaqus modeling are within a satisfactory range, thus the reliability of Navier solution and Abaqus modeling method are generally attested. From this figure, it clearly shows that the local response in this case is mainly higher than those of the global response. In contrast to support frame cases, the local and global displacements in this case are usually smaller. Since not only the downward movement but also upward movement of the steel plate on all four edges were presumed as zero using the boundary condition definition, the steel plate supposed to move lesser than those with support frame. Thus, even though the applied contact force in this case is greater than those with the support frame, their displacements are still smaller than those in the support frame. Moreover, the contact duration that was obtained by Navier solution is smaller than those of the Abaqus. This may be due to the fact that the Navier solution does not consider the interaction reaction between the colliding bodies. It just presumes the change of the velocity for the colliding bodies based on the coefficient of restitution.

In term of Abaqus Manual 6.12 Getting Stated with Abaqus-Interactive Edition [18], energy output is an effective tool that can assist in evaluating whether an Abaqus/Explicit simulation is assessing a qualified response. It is particularly crucial in checking the accuracy of the 
solution in an explicit dynamic analysis (Abaqus 6.12 Analysis User's Manual-Volume 2: Analysis [19]. In this study, the output responses that obtained from all the Abaqus simulations had been verified and only the case of $0.15 \mathrm{~m}$ hammer height impaction with boundary conditions definition which is the last case discussed previously is shown in Fig. 8 . First of all, it can be notified from the first figure that the total energy (Etotal) of the system is constantly equal to zero. This verified the accuracy of the model since Abaqus Manual states that Etotal should be a constant or approach to a constant. In the simulation of hammer drop test, the hammer free falls at the starting of Step-1. Therefore, the kinetic energy (ALLKE) increases until the hammer impacting the steel plate. The first impaction displaces the steel plate, thus, reducing the kinetic energy and increase the internal energy. When the reaction force of the steel plate transfers back to the hammer, the internal energy decreases and the kinetic energy increases. As the hammer rebounds upward, the kinetic energy decrease and subsequently, increase back as the hammer impact again the steel plate.
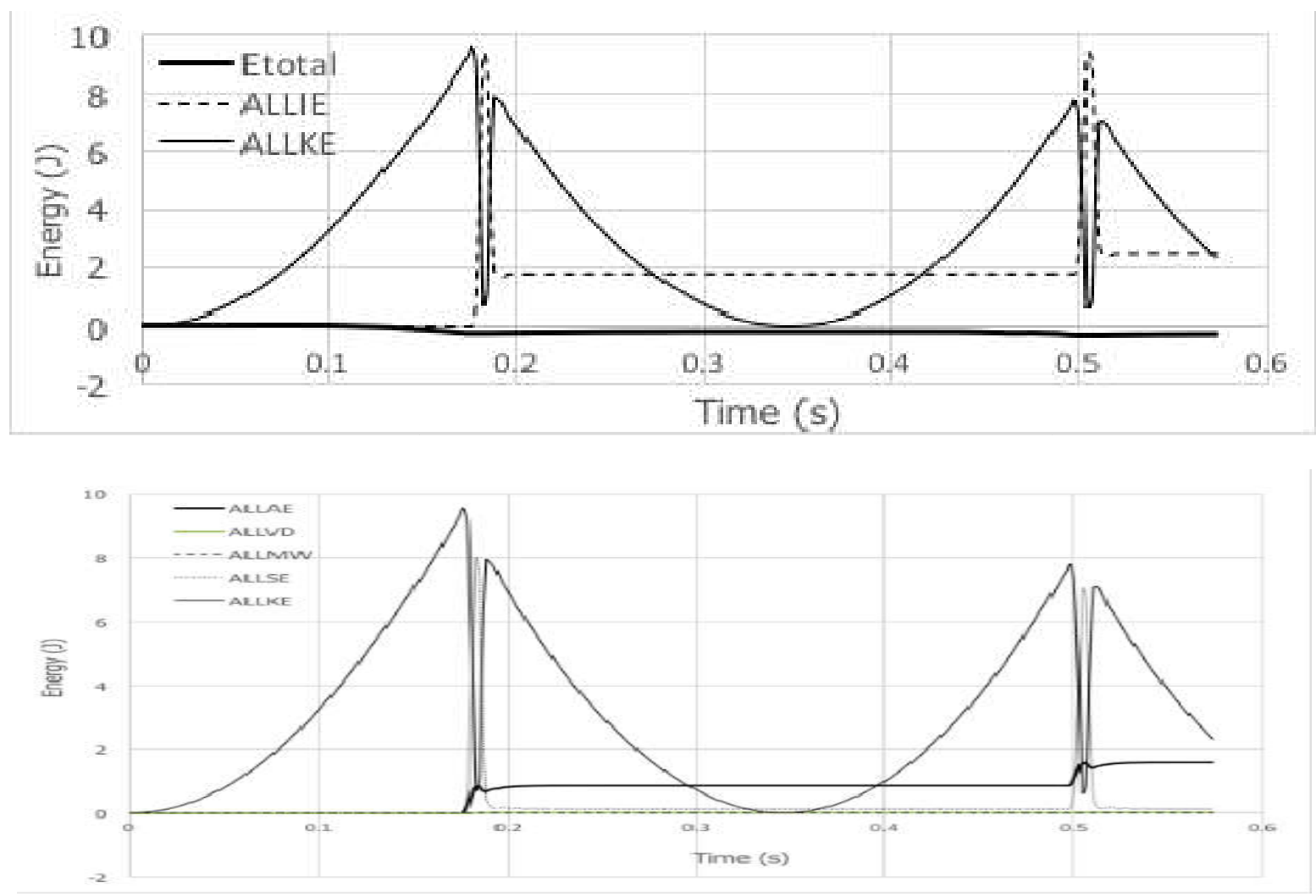


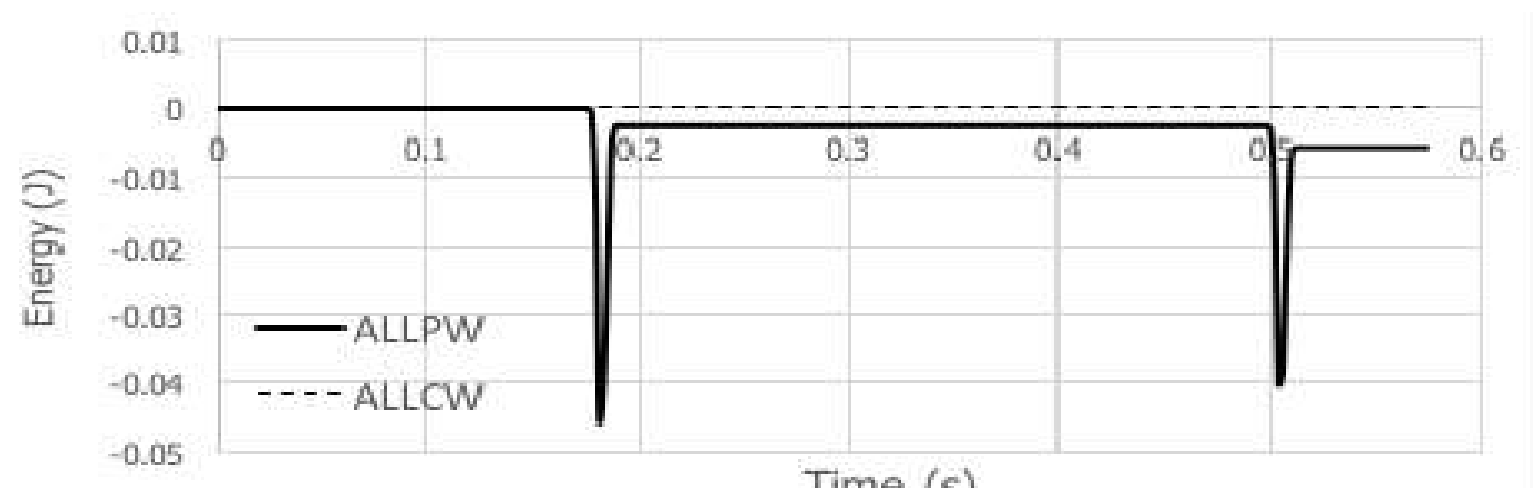

Fig.8. The energy response of whole model (boundary conditions) due to the impaction of the $0.15 \mathrm{~m}$ height hammer

Abaqus 6.12 Analysis User's Manual-Volume 2: Analysis [19] also states that the artificial strain energy (ALLAE), the damping dissipation energy (ALLVD) and the mass scaling work (ALLMW) should have negligible value if compare to the real energies like the strain energy (ALLSE) and the kinetic energy (ALLKE). These energy outputs are shown in the second figure of Fig. 8 and the trend of the energy output follows well the mentioned guideline of Abaqus. Moreover, Abaqus 6.12 Analysis User's Manual-Volume 2: Analysis [19] also mentions that the constraint penalty work (ALLCW) and the contact penalty work (ALLPW) in the analysis which involving contact should be near to zero. The third figure of Fig. 8 has illustrated this tendency.

Lastly, the stress responses of the steel plate with boundary condition towards the percussion of $0.15 \mathrm{~m}$ height hammer at discrete time step are shown in Fig. 9. With $2 \mathrm{~ms}$ of Step-2, the hammer did not touch the steel plate. Therefore, the stresses at all the points were zero. When the time step is $4 \mathrm{~ms}$, the hammer start contacted with the steel plate and the interaction getting closer until $0.01 \mathrm{~s}$ of Step-2. The maximum stress increased up to $824 \mathrm{Mpa}$ at this time step. Subsequently, the rebound of the hammer occurred and the hammer lost contact with the steel plate. Hence, big portion of the stress removed from the steel plate model and the remain stress value became $423 \mathrm{MPa}$. 

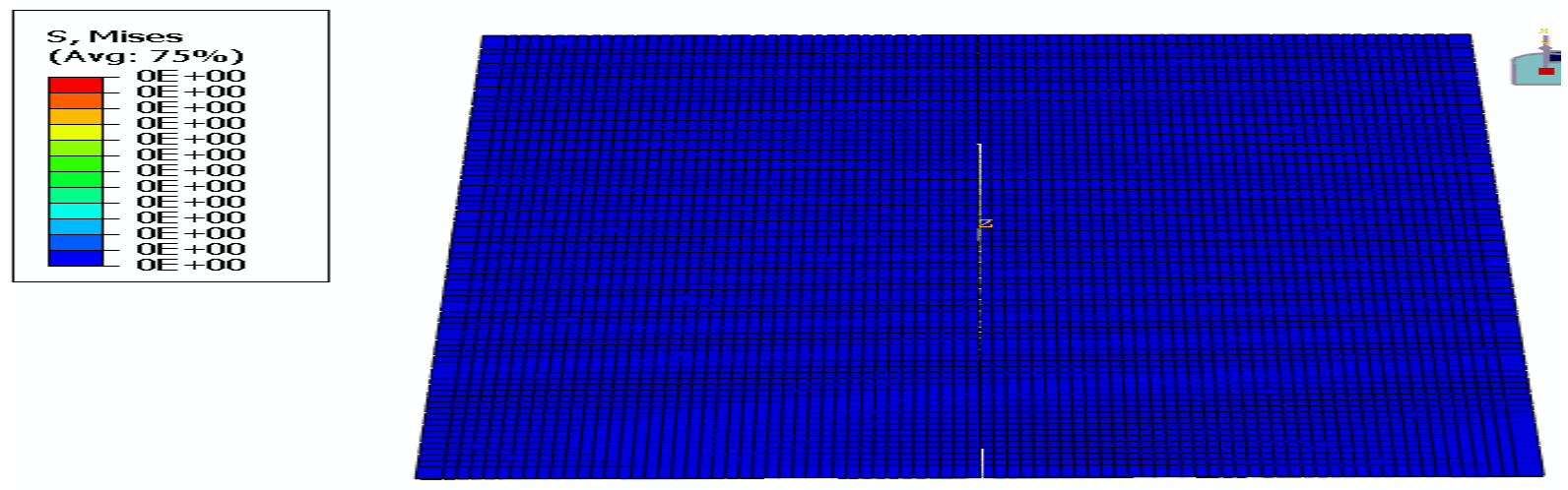

$\times$ ODB: 40_BCs_HDO15m_BE_SM20172.odb Abaqus/Explicit 6.13-1 Sun Apr 17

* Step: step-2

Primement 10305 : Step Time = 2.0000E-03

Primary Var: 5 : Mises formation Scale Factor : +1e+oo
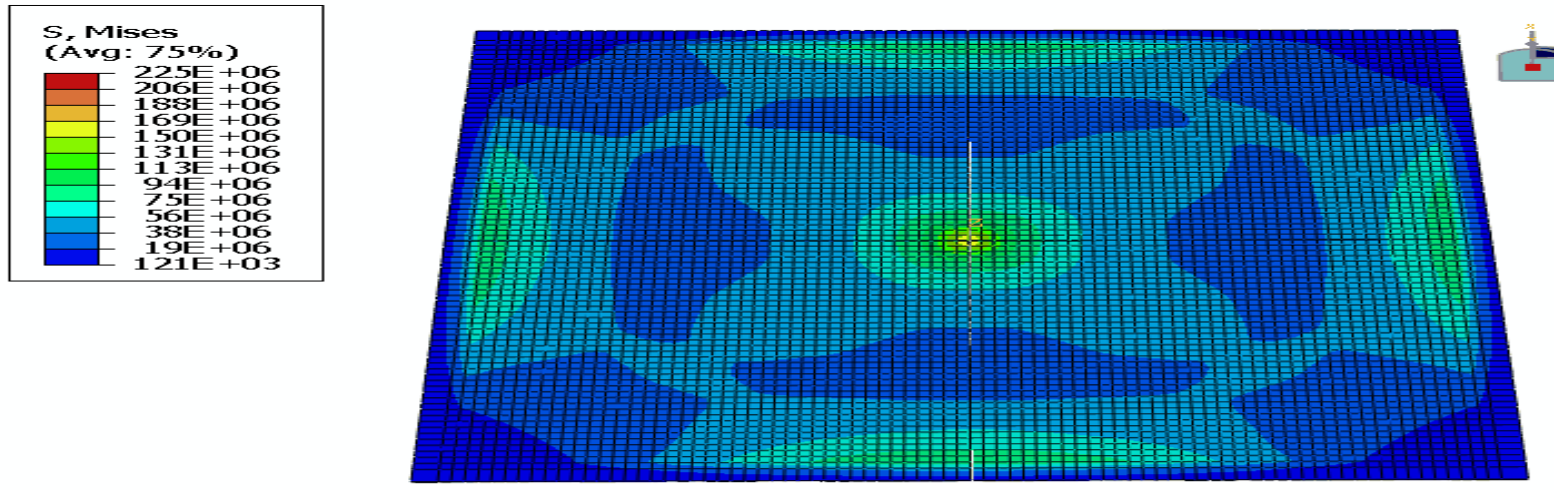

$\times$ ODB: 40_BCs_HDO15m_BE_SM20172.adb Abaqus/Explicit $6.13-1$ Sur Apr 17 * - Step: Step-2 $21954:$ step Time = 4.0001E-03

Primaryvar: 5 Mises Peformed var: Deformation scale Factor : +1e+oo
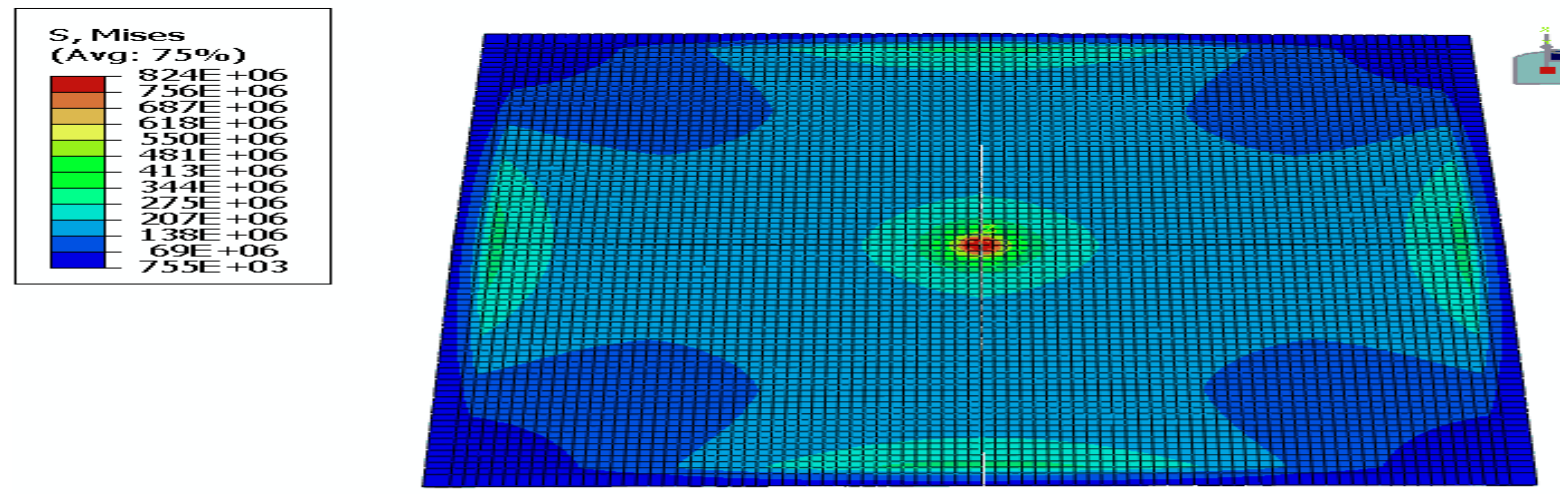

$\times$ ODB: 40_BCs_HDO15m_BE_SM20172.adb Abaqus/Explicit $6.13-1$ SLn Apr 1 J

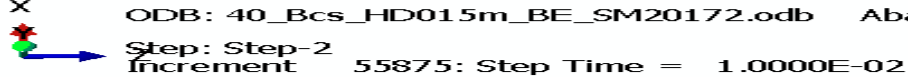

Primary Var: 5 Mises Deformed Var : Deformation scale Factor : +1e+oo 


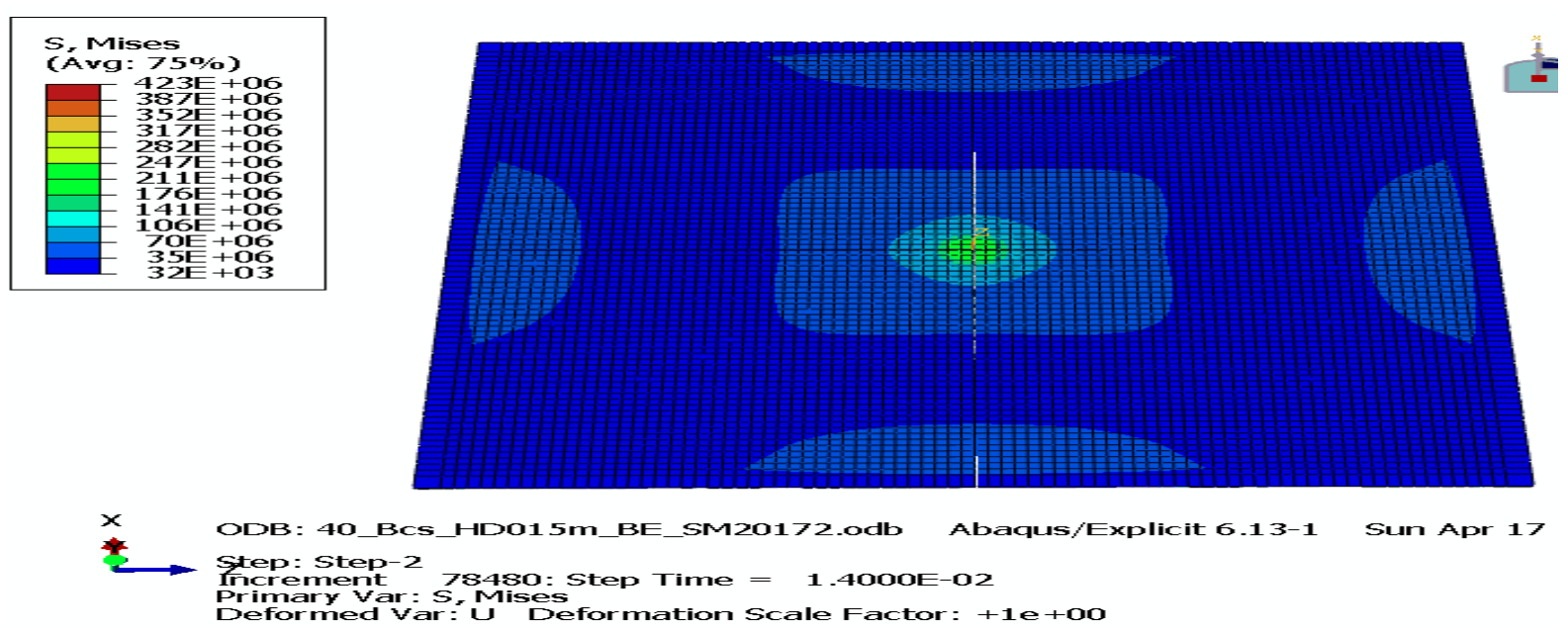

Fig.9. The stress response of steel plate (boundary condition) due to the impaction of the

$$
0.15 \mathrm{~m} \text { height hammer at different time step }
$$

In order to clearly demonstrate the stress scattering of the steel plate, the stress distribution of the steel plate with boundary condition due to the impaction from the height of $0.15 \mathrm{~m}$ hammer is illustrated in Fig. 10. In general, the applied stress that distributed to various points of the steel plate had varied values. Yet, these values were symmetrical from left to right and top to bottom. While the projectile dropped at center point of the steel plate and four edges of the steel plate were simply supported, the impact stress spreads symmetrically to the steel plate. The displacement responses that were captured experimentally and simulate with Abaqus from Fig. 4 to Fig. 7 also verified this phenomenon and the reliability of the Abaqus simulation.

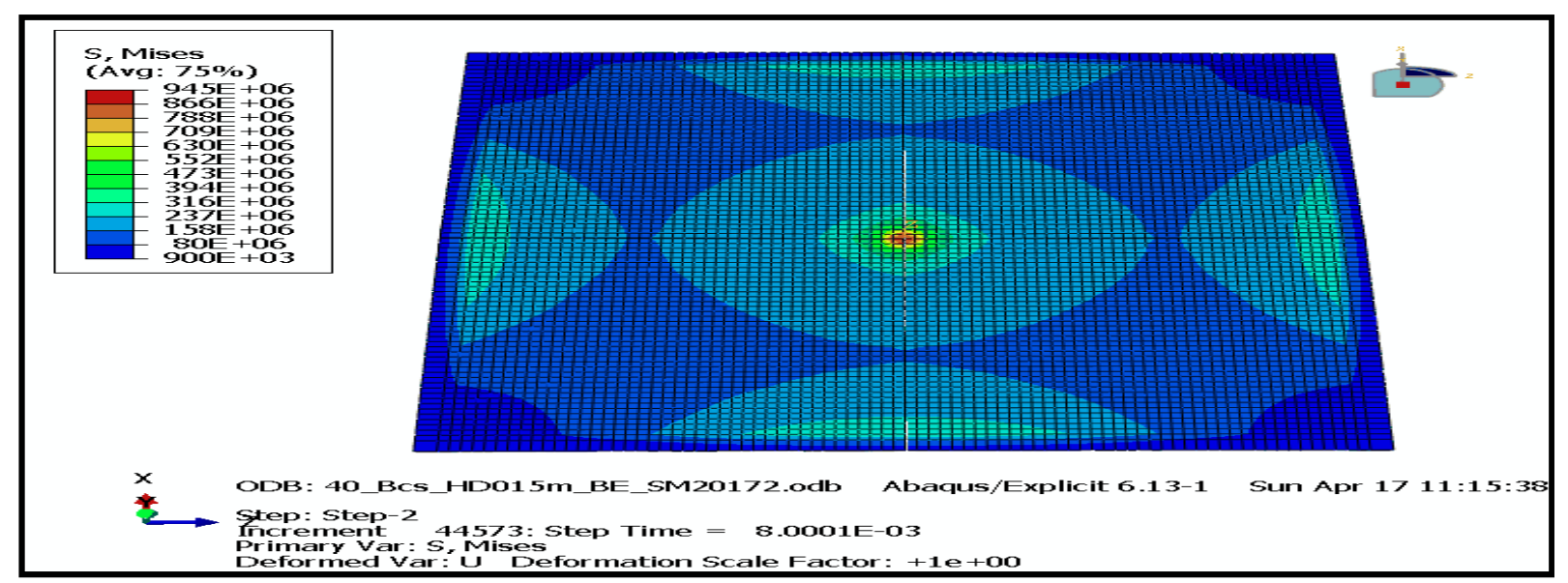

Fig.10. The stress distribution of steel plate (boundary condition) due to the impaction of the $0.15 \mathrm{~m}$ height hammer at $0.1 \mathrm{~s}$ after the hammer impacted the steel plate 


\section{CONCLUSION}

The impact response of the four edges simply supported steel plates in the hammer drop test have been measured experimentally, analyzed theoretically with Hertz impact law and Navier solution and modelled numerically with FEM software, Abaqus. Experimental results have attested the creditable of the Abaqus modelling. The contact forces that acquired from Hertz impact law and Abaqus agree very well with each other. Both of them are good approaches in evaluating the contact forces. Two different types of boundary condition were modelled with Abaqus. Both of these results have good accuracy. However, Navier solution is only restricted to analyze local response and certain boundary condition. In short, FE analysis can compensate the limitation of analytical methods and it has high potential in investigating the impact response of other structures prudently.

\section{ACKNOWLEDGEMENTS}

The authors wish to express the deepest gratitude to the financial assistance from Ministry of Higher Education (MoHE) under MyBrain15 program, MyPhD scholarship and Fundamental Research Grant Scheme (FRGS), Grant No. FRG0350-TK-2/2013. Moreover, the support from Centre for Postgraduate Studies, Universiti Malaysia Sabah is also very much appreciated.

\section{REFERENCES}

[1] Mohamed A K, Ahmed F. Mild steel plates impacted by hard projectiles. Journal of Constructional Steel Research, 2014, 99:57-71

[2] Lin-Hai H, Chuan-Chuan H, Xiao-Ling Z, Kim J R R. Behaviour of high-strength concrete filled steel tubes under transverse impact loading. Journal of Constructional Steel Research, 2014, 92:25-39

[3] Nadeem AS, Baha MAK, Tarek HA, Yousef AA, Rizwan AI, Husain A. Reliability of RC shielded steel plates against the impact of sharp nose projectiles. International Journal of Impact Engineering, 2014, 69:122-135

[4] Stronge W. J. Impact mechanics. New York: Cambridge University Press, 2000 
[5] Janete A, Nuno P, Miguel T D S, Paulo F, Hmaid M L. A comparative study of the viscoelastic constitutive models for frictionless contact interfaces in solids. Mechanism and Machine Theory, 2015, 85:172-188

[6] Parvis M, Mojtaba D. Low velocity impact analysis of functionally graded carbon nanotubes reinforced composite skew plates. Composite Structure, 2016, 140:728-748

[7] Rimantas K, Harald KE, Evaldas Z, Darius M. Comparative evaluation of normal viscoelastic contact force models in low velocity impact situations. Advanced Powder Technology, 2016, 27(4):1367-1379

[8] Shilei H, Oliver A B. A novel, single-layer model for composite plates using local-global approach. European Journal of Mechanics A/Solids, 2016, 60:1-16

[9] Elavenil S, Knight G M S. Impact response of plates under drop weight impact testing. Daffodil International University Journal of Science and Technology, 2012, 7(1):1-11

[10] Wencong S, Li X F, Wang C Y. Bending of a rectangular plate with rationally restrained edges under a concentrated force. Applied Mathematics and Computation, 2016, 286:265-278 [11] Ramesh K. T. Springer handbook of experimental solid mechanics. New York: Springer Science + Business Media, 2008

[12] Devdas S., Richard A. K. Mechatronics system design. New York: Cengage Learning, 2011

[13] Hertz H. Miscellaneous papers. London: Macmillan, 1896

[14] Peter O. K. K. History of shock waves, explosions and impact: A chronological and biographical reference. Berlin: Springer-Verlag, 2009

[15] McLaskey G C, Glaser S D. High-fidelity conical piezoelectric transducers and finite element models utilized to quantify elastic waves generated from ball collisions. In SPIE Sensors and Smart Structures Technologies for Civil, Mechanical and Aerospace Systems, 2009, pp. 1-8

[16] Hoppmann W. Shock and vibration handbook. New York: McGraw Hill, 1995

[17] Werner S. Vibrations of shells and plates. New York: Marcel Dekker Inc., 2004

[18] Simulia. Abaqus 6.12, Getting started with Abaqus-Interactive edition. Rhode Island: Simulia, 2012 
[19] Simulia. Abaqus 6.12, Analysis user's manual-Volume 2: Analysis. Rhode Island: Simulia, 2012

\section{How to cite this article:}

Chong CS, Rao NSVK, Mariappan M. Finite element modelling of four edges simply supported steel plate under impact load. J. Fundam. Appl. Sci., 2017, 9(3S), 257-278. 